Document downloaded from:

http://hdl.handle.net/10251/77891

This paper must be cited as:

Furió Ferri, D.; Juan, M.; Segui, I.; Vivó Hernando, RA. (2015). Mobile learning vs. traditional classroom lessons: A comparative study. Journal of Computer Assisted Learning. 31(3):189201. doi:10.1111/jcal.12071.

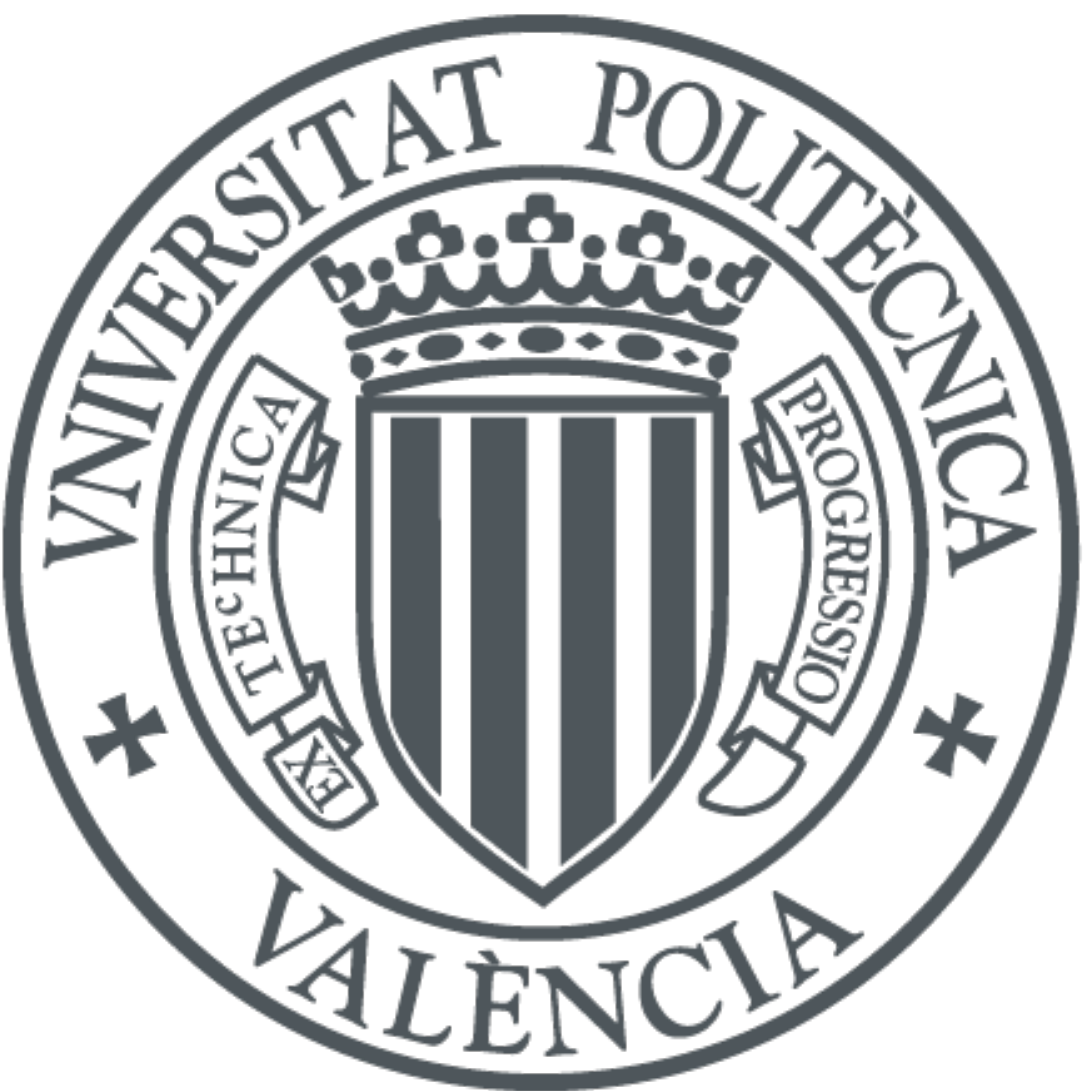

The final publication is available at

http://dx.doi. org/10.1111/jcal.12071

Copyright Wiley

Additional Information 


\section{Mobile learning vs. traditional classroom lessons: a comparative study}

David Furió $^{1}$; M.-Carmen Juan ${ }^{* 1}$; Ignacio Seguí ${ }^{2}$; Roberto Vivó ${ }^{1}$

\footnotetext{
${ }^{1}$ Instituto Universitario de Automática e Informática Industrial, Universitat Politècnica de València, C/ Camino de Vera, s/n. 46022 Valencia, Spain

${ }^{2}$ AIJU, Ibi, Alicante, Spain

* mcarmen@ai2.upv.es; mcarmen@dsic.upv.es
}

Abstract

Different methods can be used for learning, and they can be compared in several aspects, especially those related to learning outcomes. In this paper, we present a study in order to compare the learning effectiveness and satisfaction of children using an iPhone game for learning the water cycle vs. the traditional classroom lesson. The iPhone game includes multiple interaction forms (touch-screen interaction and accelerometer) and combined Augmented Reality (AR) mini-games with non-AR mini-games. The traditional classroom lesson had the same learning content as the iPhone game. Thirty-eight children from 8 to 10 years old participated in the study. The analyses of the pre-test and the post-tests showed that the children made significant learning gains about the water cycle, regardless of the method used. Even though the results showed that the iPhone method achieved higher knowledge results than the traditional classroom lesson, no statistically significant differences were found between the iPhone and the classroom lesson. When analysing the motivational outcomes, the results showed that the children found the iPhone game to be more satisfying than the classroom lessons. Since the iPhone game achieved similar learning results and a higher motivational effect than the classroom lesson, this suggests that games of this kind could be used as a tool in primary schools to reinforce students’ lessons.

Keywords: Mobile Game-based Learning, iPhone Game, Augmented Reality, Learning Outcomes

\section{Introduction}

A new generation of children has grown up playing with computer games and using mobile devices and other technological devices. They have developed a different set of attitudes and aptitudes, which may have created a disconnect between their expectations and the learning environment found in classrooms (Oblinger, 2004). One of the reasons for this failure is that this new generation of children is being educated with old methods (Prensky, 2001; Beck \& Wade 2006). In a time when children handle digital information, communicate with others via mobile technologies, and play more games than previous generations (Beck \& Wade, 2006), game-based learning might be a more appropriate approach for teaching and engaging the children in a more successful way than traditional learning methods (Prensky, 2001).

Games have many of the attributes of effective learning environments, like elements of urgency, complexity, learning by trial-and-error, and scoring points. They also support active learning, experiential learning and problem-based learning, and they also provide immediate feedback (Oblinger, 2004). Two other important features that games have are interactivity and engagement. These two features can lead to deeper learning. Games combined with curricular 
content hold the potential to make learning in traditional environments like classrooms easier, more engaging, and more effective (Prensky, 2001).

Having motivated learners is what many teachers desire, and motivation is an aspect in which games can excel. Motivation is associated with students' desire to participate in activities. According to Malone and Lepper (1987), there are seven factors that promote motivation: challenge, curiosity, control, fantasy, competition, cooperation, and recognition, many of which are present in games (Prensky, 2001).

Mobile Game-Based Learning

Mobile learning (M-learning) is a new learning paradigm that exploits the use of mobile devices in education (Sharples, Corlett, \&Westmancott, 2002). Mobile platforms are rapidly becoming the platform of choice for casual games. More and more teenagers play games on their mobile devices. These mobile devices make the educational process flexible and adaptable for students as well as for the schedules of schools and the needs of teachers (Klopfer, Sheldon, Perry, \& Chen, 2012) since they can be used anywhere/anytime (Jones \& Jo, 2004). Mobile game-based learning also enables immersion and promotes motivation in a mixed reality environment (Schwabe \& Göth, 2005).

Augmented Reality

A commonly accepted definition for AR defines it as a system that has these three features (Azuma, 1997):

1) It combines real and virtual objects.

2) It has real-time interaction.

3) It has 3-D registration.

AR systems can use one or more of the following technologies to capture data from the real world: digital cameras, optical sensors, accelerometers, GPS, etc. The iPhone used in the study presents a combination of some of these elements, making it a suitable platform for AR.

With AR technology, traditional teaching materials are preserved and supplemented by virtual content, which can enhance the students' learning and motivation. Therefore, AR could be used in the schools to improve the learning environment (Tan, Lewis, Avis, \& Withers, 2008). Motivation and objectives

In this paper, we present a study to determine which method (iPhone game or traditional classroom lesson) is better suited for learning and motivating children. Our first decision was whether to use a smartphone or a Tablet PC and which model. These types of devices have two major differences: their screen size and weight. In a previous work, Furió et al. (2013), it has been demonstrated that the different characteristics of these devices do not affect the learning outcomes, usability, or engagement of the children. Even though, we could have used either, we chose to use an iPhone. However, similar studies using other types of mobile devices could be carried out. Our iPhone game combines AR and non-AR mini-games and uses multiple interaction forms (touch-screen interaction and accelerometer). The main objectives of this study were to determine if the game helped children in the learning process and to check which method (the iPhone game or the traditional classroom lesson) had more influence on the participants regarding acquired knowledge and satisfaction. The primary hypothesis was that playing the iPhone game would lead to at least equivalent learning results as the traditional lesson and that children would prefer the iPhone game. One of the reasons on which we base our hypothesis is the fact that children belong to the 'gamer generation' (Beck \& Wade, 2006). To prove this hypothesis, we used questionnaires and observations that were designed by the people in charge of the trials. To test the primary hypothesis, we evaluated the quantitative data obtained from the questionnaires using ANOVAs. 
The reasons why we conducted this study were the following:

1) There is little experience in the use of mobile game-based learning (Lavín-Mera, Moreno-Ger, \& Fernández-Manjón, 2008).

2) AR has not been exploited for mobile learning games.

3) Prior studies have focused more on motivational aspects than on learning outcomes (Papastergiou, 2009).

4) There are very few uses of mobile technology or games for learning in classrooms (Klopfer, Sheldon, Perry, \& Chen, 2012).

5) To our knowledge, this is the first work in which a mobile game of these characteristics is compared with a traditional classroom lesson.

The paper is organized as follows. Section 2 focuses on the state of the art in game applications related to learning in school environments. Section 3 describes the iPhone game. Section 4 presents the study. Section 5 presents the results, and Section 6 presents the conclusions and future research.

\section{Related work}

As stated above, there are few works that use AR technology in mobile game-based learning, and the majority of those works are centred on the usability and motivational aspects of the game used. One of these works is HELLO, which is an English learning system that used QR codes and AR (Liu, Tan, \& Chu, 2010). Twenty students equipped with a PDA participated in the study. The results showed that the majority of the students found the course easy to use and useful for assisting learning. The results also indicated that HELLO not only increased the students' motivation to learn, but also enhanced their learning outcomes.

Next, we cite some works that have compared games that do not include AR with more traditional learning environments and have analysed the learning outcomes. In 2009, Tüzün et al. (Tüzün, Yılmaz-Soylu, Karakus, Inal, \& Kızllkaya, 2009), selected Quest Atlantis (QA) for their experiments with an educational computer game to teach primary school students about geography. The game contained $2 \mathrm{D}$ and $3 \mathrm{D}$ environments. The students used the keyboard or the mouse to interact with the game. A total of 24 students from the fourth and fifth grades participated in the study. Pre-test and post-test were used to evaluate the learning gains. The results showed significant results regarding the acquired knowledge when playing the game. When compared to the traditional school environment, the students playing the game showed statistically significant higher motivations. In the same year, 2009, Papastergiou (Papastergiou, 2009) developed LearnMem1, a computer game for learning computer memory concepts. The game was designed in accordance with the curricular objectives and the subject matter of the Greek high-school Computer Science curriculum. LearnMem1 used environments that combined access to hypermedia learning material (webpages) with game playing. LearnMem1 was compared to LearnMem2, an educational website on computer memory, which had the same concepts taught in LearnMem1. A total of 88 students between 16 and 17 years old participated in the study. They were divided into two groups. One of the groups used the LearnMem1, while the other used LearnMem2. They used a pre-test and a post-test in order to compare the knowledge acquired. The results showed that LearnMem1 was more effective in promoting students' knowledge of computer memory concepts and more motivational than LearnMem2. The acquired knowledge and the motivational effect of LearnMem1 did not differ significantly between boys and girls. In 2011, Sandberg, Maris, and de Geus developed the MEL-application (Sandberg, Maris, \& de Geus, 2011) for the goal of learning English. The subject of the game was animals. The MEL-application could be used both during a visit to the zoo (where the children were led to the different animals by GPS) and at home, (where the children could access 
the different continents and animals, in any order). Five different game types were included in the application. This study used pre-test and post-test questionnaires to measure the individual change in mastery of a set of targeted English words. A total of 85 fifth-graders participated in the study. They were divided into three groups. The first group had classroom lessons in English about zoo animals and their characteristics. The second group took classroom lessons and worked with MEL in a public zoo. The third group received the same treatment as the second but could use the MEL application outside of the classroom lessons. They used T-mobile Pulse smartphones with a GPS and a touch-screen interface. The results showed that the group that took the mobile phone home improved the most since they had additional learning time. The results also indicated that the students were motivated to use the application in their spare time, which benefitted their learning. In 2013, Al-Qahtani and Higgins investigated the effects of elearning, blended learning, and classroom learning (Al-Qahtani, \& Higgins, 2013). The study used a pre- and post-test questionnaire to measure the learning outcomes. Three groups were involved: the first group was taught by e-learning, the second group by blended learning (which combines e-learning and traditional teaching), and the third group was taught using the traditional teaching. The sample consisted of 148 students: 43 students in the first group, 55 students in the second group, and 50 students in the third group. The Ethics unit from an Islamic Culture course was selected for the study and adapted for the online course (the e-learning method). The results showed that there was a statistically significant difference between the blended learning method and the other two methods. However, no significant difference was found between the e-learning and traditional learning groups. Girard, Ecalle, \& Magnan, (2013) also analysed studies that compared the use of game-based learning tools with more traditional approaches. The conclusion was in line with the studies described in this section: the games had the same learning effect as the traditional approaches.

\section{Description of the game}

\section{Method}

The main objective of the game we have developed is to reinforce children's knowledge about the water cycle. The content of the game was extracted from the textbooks used in the courses of the third and fourth grades of the authors' country. In this game, the children learn about the water cycle, water composition, and water pollution. The major processes of the water cycle are explained to the children. The first stage of the water cycle that the children see is the evaporation phase. Next, they see the condensation phase. The third water cycle phase they see is precipitation. The last phase is collection. Apart from the water cycle, the children also learn what objects can pollute the water and what elements make up water.

The game has seven mini-games in total. All the mini-games show the players' current status on the screen. Several mini-games use AR technology, the children have to explore a room looking for the objects requested by the guide character. A drop of water represents the guide character. To search for the objects, the children must focus the device's camera on the different markers distributed around the room. In the study, ten different AR markers were used and placed in the activity room as shown in Figure 1. When the children selected an object, a message was displayed telling them whether the object picked up was the right one. Non-AR mini-games appeared in combination with some AR mini-games. The non-AR mini-games did not use AR, but they used tactile or accelerometer capabilities. Between each mini-game (AR and non-AR), video and audio explanations were displayed, describing the rules and goals to complete the next mini-game. They also served as a reward for the children when they had completed a mini-game, showing what they had achieved. This way, all the mini-games are 
linked together in a continuous story thread. Next, we explain in more detail each one of the mini-games, which are shown graphically in the flowchart in Figure 2:

1. The game started with a video, which introduced the children to it. Next, they searched the room looking for the guide character. This mini-game was the first contact with the AR system. It served as a tutorial and helped the children to learn to focus and to select objects in the AR mini-games.

2. Once the guide character had been found, the next mini-game required the children to form three water drops from oxygen and hydrogen atoms. The atoms were represented as different coloured drops of water with the letter ' $\mathrm{H}$ ' or ' $\mathrm{O}$ ' on them. The children had to select two hydrogen atoms and then an oxygen atom in the following order: 'H-H-O'. Then, a drop of water was formed. Figure 3 shows a child playing this mini-game.

3. Once the children made three drops of water, they went to the first non-AR mini-game. The mini-game consisted of collecting twenty suns in order to evaporate the drops of water they had made before. This mini-game corresponded to the evaporation stage in the water cycle. The suns fell from the top of the screen and the children had to move a water drop that was at the bottom of the screen from left to right using the tactile screen capabilities of the device (Figure 4).

4. When the twenty suns were collected, a new non-AR mini-game that used the accelerometer capabilities started. Here, the children had to place ten clouds over a mountain peak by tilting the device (Figure 5).

5. The third AR mini-game corresponded to the condensation stage of the water cycle. In this mini-game the children had to find thermometers with low temperatures (represented by the colour blue) to cool the clouds and produce precipitation. There were also thermometers with high temperatures (represented by the colour red).

6. The next mini-game corresponded to the collection phase. Here, the children had to collect twenty drops of water that were falling from the mountain peak by touching them. This completed the water cycle.

7. In the last mini-game, the guide character requested the children to clean a river by removing the pollutant objects. To do this, they had to pick up the pollutant objects using the AR capabilities of the device.

A more detailed explanation about the iPhone game, including theoretical underpinnings and design guidelines can be found in Furió et al. (2013).

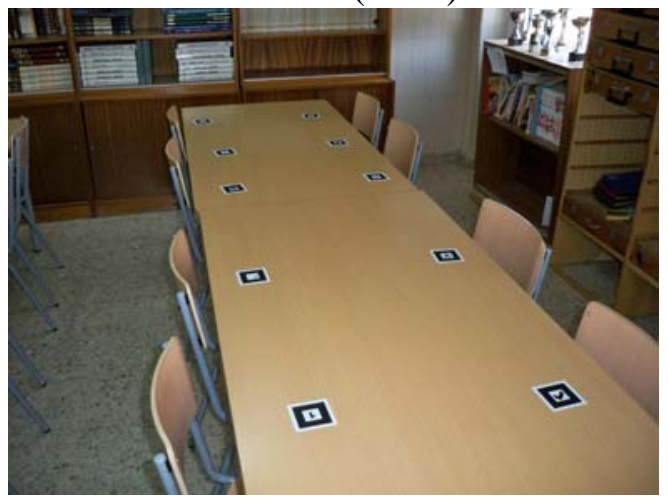

Figure 1. The markers used in the iPhone game. 


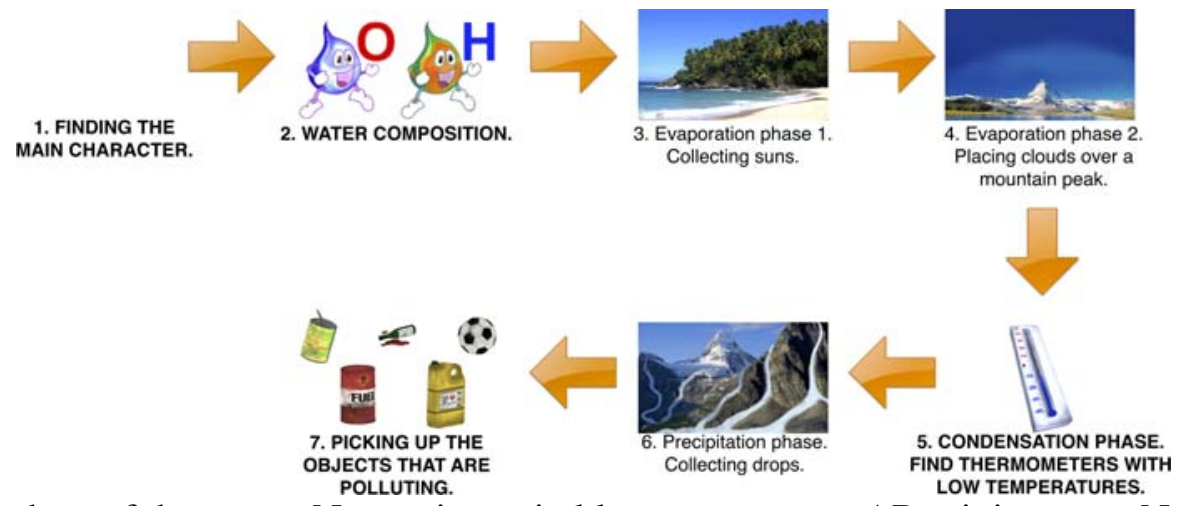

Figure 2. Flowchart of the game. Names in capital letters represent AR mini-games. Names in normal print represent non-AR mini-games.

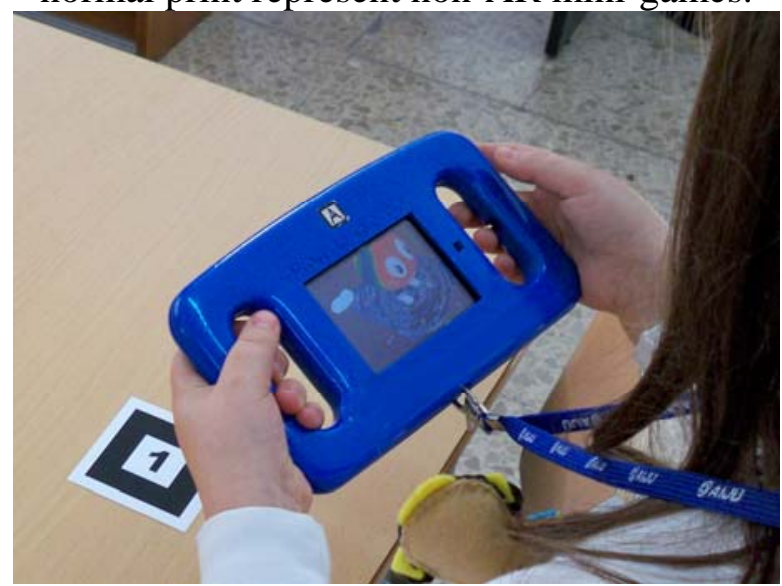

Figure 3. A child trying to form a water drop. She is searching for water drops with the letters $\mathrm{H}$ and $\mathrm{O}$.

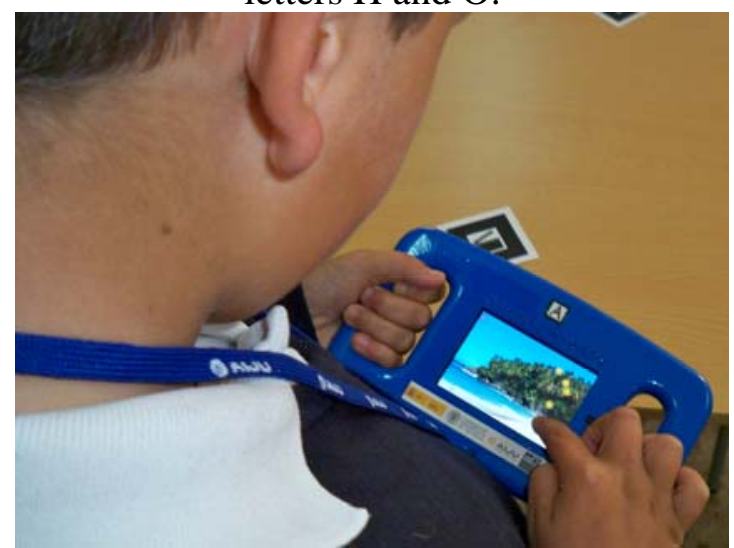

Figure 4. A child is collecting the suns. 


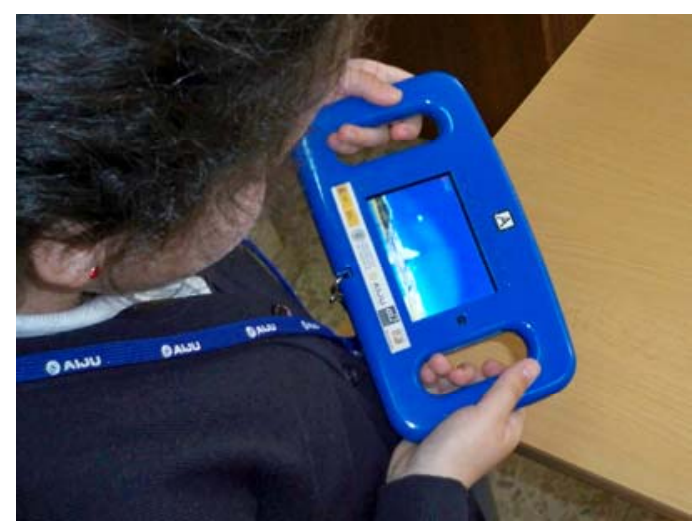

Figure 5. A child tilting the device in order to place the clouds over the mountain peak.

\section{Hardware and Software}

An iPhone 3GS with iOS version 4.3 was used during the evaluation. The device has a built-in camera that allows the real world to be recorded and displayed on the screen as well as an accelerometer.

To develop and run the iPhone game, we used the Xcode 4 IDE and the iPhone SDK 4.3. The software that was used to include AR capabilities on the iPhone was ARToolKitPlus 2.1.1. We used SIO2 1.4 version, a 2D/3D game engine with OpenGL-ES 1.1 capabilities designed for mobile devices (http://www.sio2interactive.com). The engine also provided the necessary functions, methods, and scripts to import, load, and animate 3D scenes created in Blender, which was used in our game to create 3D objects.

To protect the device from shocks and falls, an external case was made (Figure 3). It also had a ribbon that the children could put around their necks in order to provide more stability when holding the device.

\section{Participants}

Study

The target age (8-10 years old) was defined taking into account the content and courses used to design the game and the experience of a pedagogical group that participated in the project. Thirty-eight children from 8 to 10 years old -with a mean age of 8.71 \pm 0.65 : 20 boys (53\%) and 18 girls (47\%) - participated in our study. These children were attending the Engeba school of Valencia (Spain).

\section{Measurements}

A total of five questionnaires were used. One was the pre-test which was given to all of the children. Another questionnaire was filled out by the group playing the water cycle game and by the group taking the traditional classroom lesson. Later, the two groups changed activities and played the game or took the traditional lesson and the other questionnaire was filled out. While most of the answers to the questions followed a Likert scale ranging from 1 to 5 , others had categorical answers and, in some cases, hand-written answers.

The pre-test (Q1) was composed of 6 questions designed to evaluate how much the children knew or remembered about water from school (composition (Questions \#1, \#2), cycle (Questions \#3, \#4, \#6), and pollutants (Question \#5)). In order not to prolong the test phase, the number of questions was limited to the minimum. These questions (\#1-\#6) were multiple-choice question with 4 possible answers scored as success or fail, except \#5. As an example, Question \#1 was: Do you remember what comprises water? a) Hydrogen and Oxygen, b) Potassium and Sodium, c) Water is made up of nothing, d) I do not know / I do not remember. Question \#5 was: 
Check every object you think is a pollutant. Then the participants had to check every object they believed to be a pollutant from a list of nine items. To make it friendlier to the children, an image accompanied every object. For the data analysis, this question was considered to be correct if all the objects were correctly checked. Apart from the knowledge questions, we also gathered gender, grade, and age data from the participants.

The first post-game questionnaire (Q2-iPhone) (the one filled out after playing the iPhone game first) was composed of 19 questions. The first 6 questions were the same ones the participants answered in Q1. This way we could observe if they had improved their knowledge about the water cycle. The rest of the questions were about participant satisfaction and interaction with the game. In question 19, the participants had a chance to give a global score to the game.

The first post-lesson questionnaire (Q2-TR) (the one filled out after taking the traditional classroom lesson first) was composed of 10 questions. The same questions were asked as in Q2iPhone with the exception of the questions related specifically to the game and the device, which were left out.

The second post-game questionnaire (Q3-iPhone) was composed of 16 questions. Some of the questions were the same as in the Q2-TR, which allowed us to compare the traditional classroom lesson with the iPhone method. The children also had to select which learning method they preferred; they had to explain why they preferred one method over the other; and they had to describe what they liked the most about the whole experience.

The second post-lesson questionnaire (Q3-TR) was composed of 7 questions. Some of the questions were the same as in the Q2-iPhone, which allowed us to compare the traditional classroom lesson with the iPhone method. The same questions were asked as in Q3-iPhone with the exception of the questions specifically related to the game and the device, which were left out.

Procedure

The children who participated in this study were randomly assigned to one of two groups:

Group A. the group that played the iPhone game first and then the traditional classroom lesson.

Group B. the group that took the traditional classroom lesson first and then the iPhone game.

Both groups had the same number of subjects: 19 children were assigned to group A, and 19 to group B. Figure 6 shows the procedure of the study graphically. The content evaluation protocol was established in a way similar to the one applied to assess the contents in the classroom. In the classroom of the third and fourth grade of the primary education in the country of the authors of this work, the usual established dynamic is to teach a subject and then evaluate the level of learning of the content.

The traditional classroom lesson was given in a traditional classroom. The iPhone method took place in a different setting. The questionnaires were filled out in the same rooms. The iPhone classroom had two identical playing areas where two children could play simultaneously. The two playing areas had the same set of markers placed in the same positions. There was no interaction between the two children, and there was also a person with each child to guide them and to clarify their possible doubts during the whole activity. The questionnaires were filled out in the same room where the activity took place. To avoid the influences of answering the pre-test on the results of the post-tests (Q2-iPhone and Q2-TR), the children were encouraged to answer all questions without any pressure; if they did not know the answer, it was considered to be completely normal. The children were not informed whether or not their answers on the pre-test 
were correct. Thus, the children did not acquire any knowledge by answering the pre-test; they only learned during the game.

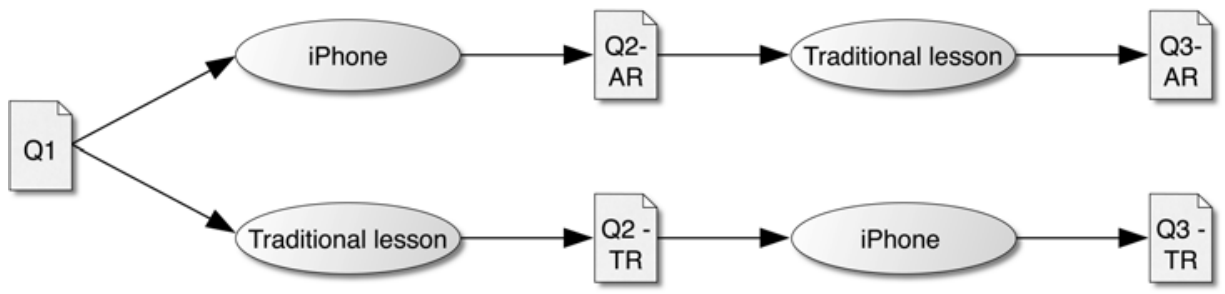

Figure 6. Study procedure.

Results

The variable of knowledge was created to condense the six knowledge questions by counting the number of correct answers. In order to have a complete understanding of the knowledge variable, we performed several analyses. A t-test was performed to observe the effect of the methods in the knowledge scores. The results showed that the scores in the post-tests $(4.82 \pm 1.20)$ were significantly higher than the scores in the pre-test $(4.05 \pm 1.04)(\mathrm{t}[37]=3.94, \mathrm{p}<$ 0.01). A mixed design ANOVA test was also performed in order to take into consideration several factors simultaneously. The factors of grade and gender were between subjects because they were observed, but the factor of questionnaire (pre-test: Q1 or post-test: Q2-iPhone+Q2-TR) was within subjects because it contained repeated measures. The results of the analysis in Table 1 showed that there were significant differences in the questionnaire factor between the pre-test and the post-test. The p-value was below 0.01. Figure 7 shows the boxplots for the knowledge scores, where the higher results of correct answers after using a method over the pre-test can be observed. Another t-test was performed to compare the methods. The results showed no significant differences between the iPhone method $(4.89 \pm 1.45)$ and the traditional classroom lesson $(4.74 \pm 0.93)(\mathrm{t}[36]=0.40, \mathrm{p}=0.69)$. A multifactorial ANOVA test was performed in order to compare both methods taking into consideration several factors simultaneously. The result of the analysis in Table 2 confirmed the results obtained in the t-test where no significant differences were found. Figure 7 shows a comparison between the iPhone method and the traditional classroom method, indicating similar results. Also, the perceived acquired knowledge by the children fit the results shown on Figure 7. On a scale from 1 to 5, the score given to how much they thought they had learned (Question \#12: Do you think you have learned new things?) was high after using the iPhone (4.79 \pm 0.54$)$ and after taking the traditional classroom lesson (4.47 \pm 0.61$)$, and there was no significant difference between the methods $(\mathrm{t}[36]=1.69, \mathrm{p}=0.10$, Cohen's d= 0.55).

\begin{tabular}{lrrrr}
\hline Factor & d.f. & $\mathrm{F}$ & $\mathrm{p}$ & Effect size $\left(\boldsymbol{\eta}_{\boldsymbol{G}}^{\mathbf{2}}\right)$ \\
\hline Gender & 1 & 0.47 & 0.50 & 0.01 \\
Grade & 1 & 3.06 & 0.09 & 0.06 \\
Questionnaire & 1 & 15.06 & $<0.01 *$ & 0.12 \\
Other interactions & 1 & $<2.98$ & $>0.09$ & $<0.06$ \\
\hline
\end{tabular}

Table 1. Mixed design ANOVA for the knowledge scores of the pre-test and post-test questionnaires. The symbol * indicates significant differences. $\mathrm{N}=38$. 


\begin{tabular}{lrrrr}
\hline Factor & d.f. & $\mathrm{F}$ & $\mathrm{p}$ & Effect size $\left(\boldsymbol{\eta}_{\boldsymbol{G}}^{\mathbf{2}}\right)$ \\
\hline Gender & 1 & 0.16 & 0.69 & 0.01 \\
Grade & 1 & 0.47 & 0.50 & 0.02 \\
Method & 1 & 0.17 & 0.68 & 0.01 \\
Other interactions & 1 & $<0.71$ & $>0.58$ & $<0.01$ \\
\hline
\end{tabular}

Table 2. Multifactorial ANOVA for the variable of knowledge of the iPhone method and the traditional classroom lesson. $\mathrm{N}=38$.

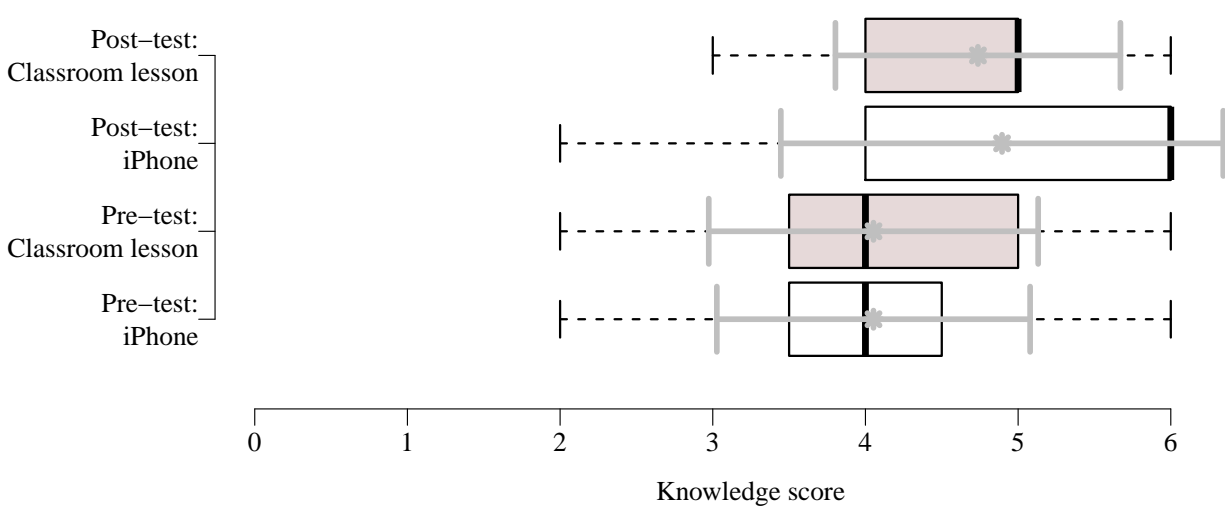

Figure 7. The scores for the knowledge questions in the pre-test and the post-test of the traditional classroom lesson and the iPhone method. The mean and standard deviation are represented with solid grey lines.

Apart from the knowledge variable, another variable of satisfaction was created to combine the answers of several questions (the mean of answers to Question \#7 (perceived fun), \#12 (perceived learning), \#16 (ease of play), and \#19 (global score, from 1 to 10)), which offers a measure of the degree of engagement and enjoyment with the game. The overall rating was very high (4.69 \pm 0.35$)$, indicating that the children were highly satisfied with both the game and the lesson. The variable was analysed using a multifactorial ANOVA with the gender, grade, and the method factors. The results of the analysis in Table 3 showed that there were significant differences in the method factor. The p-value was 0.01. Figure 8 shows the boxplots for the satisfaction scores, where higher results after playing with the iPhone method can be observed. These results indicate that the children were more satisfied with the iPhone method.

\begin{tabular}{lrrrr}
\hline Factor & d.f. & $\mathrm{F}$ & $\mathrm{p}$ & Effect size $\left(\boldsymbol{\eta}_{\boldsymbol{G}}^{\mathbf{2}}\right)$ \\
\hline Gender & 1 & 1.54 & 0.22 & 0.02 \\
Grade & 1 & 1.18 & 0.28 & 0.02 \\
Method & 1 & 8.01 & 0.01 & $*$ \\
Other interactions & 1 & $<3.07$ & $<0.08$ & 0.11 \\
\hline
\end{tabular}

Table 3. Multifactorial ANOVA for the variable of satisfaction. The symbol * indicates significant differences. $\mathrm{N}=76$. 




Figure 8. The scores for the satisfaction questions in the traditional classroom lesson and the iPhone method. The mean and standard deviation are represented with solid grey lines.

We also analyzed Questions \#7, \#12, \#16, \#19 individually. We used t-tests in order to observe if there were statistical differences between the iPhone and the classroom lesson methods. As Table 4 shows, the iPhone obtained a marginally higher result in all satisfaction questions. Furthermore, in question \#19, a statistical significant difference was found. The children scored the iPhone method significantly higher than the traditional classroom lesson.

\begin{tabular}{|l|c|c|c|c|}
\hline Questions & $\# \mathbf{7}$ & $\mathbf{\# 1 2}$ & $\mathbf{\# 1 6}$ & $\mathbf{\# 1 9}$ \\
\hline iPhone (mean \pm sd) & $4.84 \pm 0.37$ & $4.79 \pm 0.54$ & $4.58 \pm 0.61$ & $9.95 \pm 0.23$ \\
\hline Classroom lesson (mean \pm sd) & $4.58 \pm 0.51$ & $4.47 \pm 0.61$ & $4.21 \pm 0.92$ & $9.32 \pm 0.89$ \\
\hline t & 1.82 & 1.69 & 1.46 & 3.01 \\
\hline p & 0.08 & 0.10 & 0.15 & $<0.01^{*}$ \\
\hline Cohen's d & 0.59 & 0.55 & 0.47 & 0.98 \\
\hline
\end{tabular}

Table 4. T-tests of questions \#7, \#12, \#16, \#19. The symbol * indicates significant differences; $\mathrm{df}=36$.

The children's desire to continue playing the game (Question \#13: Would you like to play again to learn about new subjects?) is also an indication of the satisfaction that the children had playing the game. Independently of whether they played with the iPhone or took the classroom lesson first, all of the children indicated they would like to play the iPhone game again to learn new subjects.

With regard to the introduction of AR in the game (Questions \#9: Did you like to see how objects appeared on the black squares?, \#10: Did you like playing the games that used what you found on the black squares?), the overall rate for the enjoyment of AR games was very high (4.58 \pm 0.61 and $4.74 \pm 0.45$ for Questions \#9 and \#10, respectively). We also measured how easy it was for the children to use the AR system (Question \#14: Was it easy for you to find objects on the black squares?). The global rating was high $(4.26 \pm 0.76)$, which means that the children found it easy to play AR games. We also studied whether or not the order of playing affected the AR experience. A t-test was performed for each of the three AR questions. The results showed that no significant differences were found for Question \#9 $(t[36]=1.00, p=0.32$, Cohen's $d=$ 0.32), Question \#10 (t[36]= 1.68, $\mathrm{p}=0.10$, Cohen's $\mathrm{d}=0.55)$, or Question \#14 $(\mathrm{t}[36]=0.85, \mathrm{p}=$ 0.04 , Cohen's d= 0.28). 
A Chi-squared test for Question \#20 (What method did you like the most?) revealed that the preference for the iPhone or the traditional classroom method did not differ between the children of groups $\mathrm{A}$ and $\mathrm{B}\left(\mathrm{X}^{2}[1, \mathrm{~N}=76]=1.45, \mathrm{p}=0.23\right.$, Cramer's $\left.\mathrm{V}=0.29\right)$. Figure 9 shows the children's preference, where $100 \%$ of the children in group A and $84.21 \%$ of the children in group B chose the iPhone. Thus, we conclude that a great majority of the children preferred the iPhone to the traditional classroom lesson independently of the order of the method used.

To interact with the device, the children thought that it was easier to use the tactile screen (57.89\%) rather than tilting the device (42.11\%) (Question \#15: What did you find the easiest? [Tactile/Accelerometer]). Question \#11 (What did you like the most? [AR/Tactile/Accelerometer/None/Other]) evaluated the preferences of different types of technologies in the mini-games: AR, tactile screen, and accelerometers. The AR technology was, by a great difference, the one preferred by the children (Figure 10).

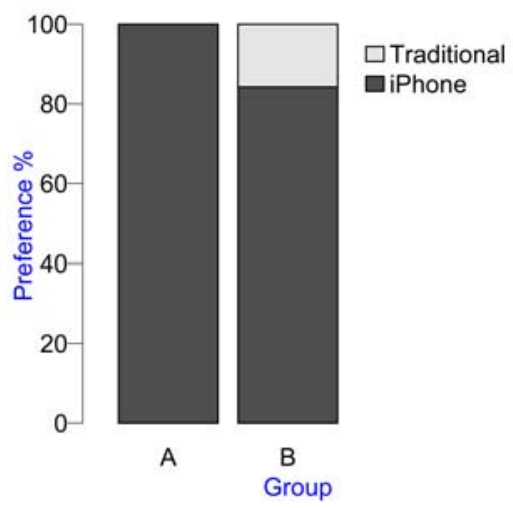

Figure 9. Preferences for the favourite method in groups A and B.

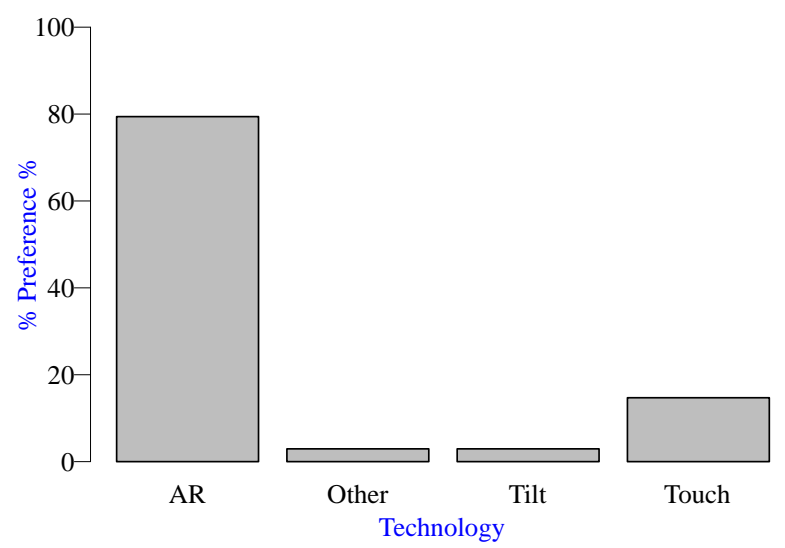

Figure 10. Preference for the favourite type of technology used in the mini-games.

\section{Conclusions}

One of the advantages of digital games is that they have a massive reach not only among children, adolescents and also adults. They also have some features that traditional teaching environments might not easily have. For example, digital games provide immediate feedback, which is useful to teachers in order to know how a student is performing in a subject. Moreover, this feedback can also be used to improve the game. Games also have features that pertain to effective learning environments like elements of urgency, complexity, learning by trial-anderror, and scoring points (Oblinger, 2004). Despite the advantages that digital games offer, not 
many educational mobile games have been studied to corroborate this. To our knowledge, this paper presents the first complete study in which an educational mobile game with special features such as AR was compared with a traditional classroom lesson. The study considers several aspects that are not usually analysed.

A study was carried out for the cognitive outcomes to determine whether children learn more by playing the iPhone game than by attending a traditional classroom lesson. The results showed significant differences in the acquired knowledge before and after using both learning methods. This indicates that the children remembered a lot of the knowledge transmitted in the game. For this reason, we can affirm that our game has been effective when it comes to transmitting knowledge in the short-term. The iPhone game also obtained higher knowledge results $(4.89 \pm 1.45)$ than the traditional classroom lesson $(4.74 \pm 0.93)$. However, no significant differences were found between the two learning methods. In other words, the children achieved similar knowledge improvements when using the iPhone game as well as when taking the traditional classroom lesson. This result corroborates our primary hypothesis ("Playing the iPhone game would lead to at least equivalent learning results as the traditional lesson”). From our point of view, this implies that the children have achieved similar knowledge improvements using an autonomous method (iPhone game) as using a guided method (traditional classroom lesson). We think this is an encouraging result because this means that children can learn anywhere and any time outside of a formal learning environment without requiring that a person supervise them. When we compare our results to other studies in which computer games have been compared with traditional methods, there is a similar trend: there are no statistical significant differences when comparing the control group with the experimental group (Tüzün, Yılmaz-Soylu, Karakus, Inal, \& Kızılkaya, 2009; Papastergiou, 2009; Sandberg, Maris, \& de Geus, 2011; Al-Qahtani \& Higgins, 2013; Girard, Ecalle, \& Magnan, 2013; previous work by the authors of this study). We also studied if there were differences in the acquired knowledge regarding the gender and grade. No significant differences were found. These are similar results to the ones obtained by Papastergiou (2009) where no significant differences with regard to the acquired knowledge were found between boys and girls. This is an excellent result because it means that the game is well suited for the two genders. On the other hand, in our view, these new methods of learning are tools that can complement traditional learning. This assumption is in line with the results of Al-Qahtani, and Higgins (Al-Qahtani, \& Higgins, 2013).

One of the principal assets of games when compared to other educational programs is the motivation for the students. Motivation, which has always been an important issue in educational programs, is associated with students' desire to participate in activities (Vernadakis, Gioftsidou, Antoniou, Ioannidis, \& Giannousi, 2012). An important clue for the motivation of players is their desire to continue interacting and playing (Price, Rogers, Scaife, Stanton, \& Neale, 2003). In our case, a total of $100 \%$ of the children indicated that they would like to play with the iPhone game again. With regard to the children's preferences, a total of $92.11 \%$ of the children preferred the experience with the iPhone game to the traditional lesson. We also studied if there were differences in the satisfaction regarding the gender, grade, and method. Significant differences were found between the traditional classroom lesson and the iPhone game in favour of the iPhone game. The reasons for why this game promoted children's learning motivation could be the following: 1) In the game, basic information was explained to the children, which was required for completing game tasks and advancing in the adventure (Sykes, 2006; Vernadakis, Gioftsidou, Antoniou, Ioannidis, \& Giannousi, 2012); 2) the learning contents are related to the school curricula, so children are able to apply what they have learned in the classroom (Oblinger, 
2004; Vernadakis, Gioftsidou, Antoniou, Ioannidis, \& Giannousi, 2012); 3) the game takes advantage of multi-sensory engagement to support experiential learning (Kiili, 2005; Vernadakis, Gioftsidou, Antoniou, Ioannidis, \& Giannousi, 2012). AR technology might have been a factor that also improved the motivation and engagement of the children in our study. AR allowed the children to explore what they were learning from a variety of different perspectives (Kerawalla, Luckin, \& Selje, 2006), thereby improving their learning experience. The studies analysed by Girard, Ecalle, \& Magnan, (2013) also suggest that games motivate the students more than traditional approaches.

Usability or perceived ease of use is considered to be an important factor that affects educational effectiveness (Jones et al., 1999; Mayes \& Fowler, 1999; Squires, 1999). A learning system with good usability can help students to focus their attention on the learning content (Sun, Tsai, Finger, Chen, \& Yeh, 2008). In our case, the iPhone game was considered easy to manipulate (4.66 \pm 0.58$)$. Thus, according to the suggestion by Sun et al., our iPhone game helps students focus their attention on the learning content.

For future work, we would like to use the iPhone itself for evaluation since it could provide immediate feedback to both students and teachers. A possible future work would be to check long-term learning. Making the game more customizable could improve the experience; for example, adapting the game difficulty to low-, mid-, and high-grade students and allowing teachers to be more involved in the game. The game could be enhanced by adding other play modes such as multiplayer (collaborative and competitive). In order to provide some learner autonomy, the game could be designed to offer a greater degree of freedom in setting the goals, difficulty, and learning activities (Sha, Looi, Chen, \& Zhang, 2012). Finally, due to the continuous improvements in mobile devices in particular, and electronic devices in general, we believe that effective educational mobile games could be developed to help in the learning process.

\section{Acknowledgments}

- This work was funded by the Spanish Government, APRENDRA project (TIN2009-14319C02).

- We would like to thank the following for their contributions:

- Noemí Rando, Encarna Torres, Sonia, Severino González, M. José Vicent, Patricia Limiñana, Tamara Aguilar, Alfonso López, Yolanda Martínez, Enrique Daunis, M. José Martínez, and Eloy Hurtado for their help.

- The Engeba school of Valencia (Spain).

- The children who participated in the study.

\section{References}

Al-Qahtani, A. A. Y., \& Higgins, S. E. (2013). Effects of traditional, blended and e-learning on students' achievement in higher education. Journal of Computer Assisted Learning, 29(3), 220-234.

Azuma, R. T. (1997). A Survey of Augmented Reality. Media, 6(4): 355-385.

Beck, J. C., \& Wade, M. (2006). The kids are alright: How the gamer generation is changing the workplace. Boston: Harvard Business School Press.

Fisch, S. M. (2005). Making educational computer games "educational”. In Proceedings of the 2005 conference on Interaction design and children, 56-61.

Fischer, G. H. (2007). Rasch Models. Handbook of Statistics in Psychometrics, 26, 515-586.

Furió, D., González-Gancedo, S., Juan, M.C., Seguí, I., Costa, M. (2013). The effects of the size and weight of a mobile device on an educational game. Computers \& Education, 64: 2441. 
Girard, C., Ecalle, J., \& Magnan, A. (2013). Serious games as new educational tools: how effective are they? A meta-analysis of recent studies. Journal of Computer Assisted Learning, 29(3), 207-219.

Jones, A., Scanlon, E., Tosunoglu, C., Morris, E., Ross, S., Butcher, P., et al. (1999). Contexts for evaluating educational software. Interacting with Computers, 11(5): 499-516.

Jones, V., \& Jo, J. (2004). Ubiquitous learning environment: an adaptive teaching system using ubiquitous technology. In Proceedings of the 21st ASCILITE conference, 468-474.

Kerawalla, L., Luckin, R., \& Selje, S. (2006). "Making it real": exploring the potential of augmented reality for teaching primary school science. Virtual Real, 10(3): 163-174.

Kiili, K. (2005). Digital game-based learning: towards an experiential gaming model. The Internet and Higher Education, 8(1): 13-24.

Klopfer, E., Sheldon, J., Perry, J., \& Chen, H.-H. V. (2012). Ubiquitous games for learning (UbiqGames): Weatherlings, a worked example. Journal of Computer Assisted Learning, 28(5): 465-476.

Lavín-Mera, P., Moreno-Ger, P., \& Fernández-Manjón, B. (2008). Development of Educational Videogames in m-Learning Contexts. In Proceedings of the Second IEEE International Conference on Digital Game and Intelligent Toy Enhanced Learning, 44-51.

Liarokapis, F., \& Newman, R. (2007). Design experiences of multimodal mixed reality interfaces. In Proceedings of the 25th annual ACM international conference on Design of communication, 34-41.

Liu, T.-Y., Tan, T.-H., \& Chu, Y.-L. (2010). QR Code and Augmented Reality-Supported Mobile English Learning System. In Mobile Multimedia Processing, Xiaoyi Jiang, Matthew Y. Ma, and Chang Wen Chen (Eds.). Springer-Verlag, Berlin, Heidelberg 3752.

Malone, T. W., \& Lepper, M. R. (1987). Making learning fun: a taxonomic model of intrinsic motivations for learning. In Aptitude, Learning, and Instruction: III. Cognitive and Affective Process Analysis, 223-253.

Mayes, J. T., \& Fowler, C. J. (1999). Learning technology and usability: A framework for understanding courseware. Interacting with Computers, 11(5): 485-497.

Oblinger, D. G. (2004). The Next Generation of Educational Engagement. Journal of Interactive Media in Education, 8(8): 1-18.

Papastergiou, M. (2009). Digital Game-Based Learning in high school Computer Science education: Impact on educational effectiveness and student motivation. Computers \& Education, 52(1): 1-12.

Prensky, M. (2001). Digital Game-Based Learning. California: McGraw-Hill.

Price, S., Rogers, Y., Scaife, M., Stanton, D., \& Neale, H. (2003). Using tangibles to promote novel forms of playful learning. Interacting with Computers, 15, 169-185.

Rasch G. (1980). Probabilistic models for some intelligence and attainment tests. Chicago: University of Chicago Press (Original work published 1960).

Sandberg, J., Maris, M., \& de Geus, K. (2011). Mobile English learning: An evidence-based study with fifth graders. Computers \& Education, 57(1): 1334-1347.

Schwabe, G., \& Göth, C. (2005). Mobile learning with a mobile game: design and motivational effects. Journal of Computer Assisted Learning, 3(21): 204-216.

Sha, L., Looi, C.-K., Chen, W., \& Zhang, B. H. (2012). Understanding mobile learning from the perspective of self-regulated learning. Journal of Computer Assisted Learning, 28(4), 366-378. 
Sharples, M., Corlett, D., \& Westmancott, O. (2002). The design and implementation of a mobile learning resource. Personal and Ubiquitous Computing, 6(3): 220-234.

Squires, D. (1999). Usability and educational software design: Special issue of interacting with computers. Interacting with Computers, 11(5): 463-466.

Sun, P.-C., Tsai, R. J., Finger, G., Chen, Y.-Y., \& Yeh, D. (2008). What drives a successful eLearning? An empirical investigation of the critical factors influencing learner satisfaction. Computers \& Education, 50(4): 1183-1202.

Sykes, J. (2006). Affective Gaming: Advancing the Argument for Game-Based Learning. In M. Pivec, Affective and Emotional Aspects of Human-Computer Interaction - Game-Based and Innovative Learning Approaches: The Future of Learning. IOS Press. 3-7.

Tan, K. T., Lewis, E. M., Avis, J. N., \& Withers, J. P. (2008). Using augmented reality to promote an understanding of materials science to school children. In ACM SIGGRAPH ASIA 2008 educators programme. (2): 8.

Tüzün, H., Yılmaz-Soylu, M., Karakus, T., Inal, Y., \& Kızılkaya, G. (2009). The effects of computer games on primary school students' achievement and motivation in geography learning. Computers \& Education, 52(1): 68-77.

Vernadakis, N., Gioftsidou, A., Antoniou, P., Ioannidis, D., \& Giannousi, M. (2012). The impact of Nintendo Wii to physical education students' balance compared to the traditional approaches. Computers \& Education, 59(2): 196-205. 